\title{
Gestión del territorio y biodiversidad en la agenda 2030: Evaluación de la política pública de gestión del lobo en su interacción con el ser humano. Estudio de caso de Galicia
}

\author{
Territory management and biodiversity in the 2030 agenda: \\ Evaluation of the public policy for the management of the wolf \\ in its interaction with the human being. Galicia case study
}

\author{
Óscar Briones Gamarra \\ Universidad de Vigo (España) \\ ORCID: https://orcid.org/0000-0003-3316-8670 \\ oscarbriones@uvigo.es
}

\begin{abstract}
NOTA BIOGRÁFICA
Doctor en Ciencias políticas (Especialidad Administración Pública) y licenciado en Ciencias Políticas (Especialidad Administración Pública). Licenciado en derecho, Máster en gestión de servicios sociales, ong's y voluntariado por la USC. Profesor universitario del Grado en Dirección y Gestión Pública de la Universidad de Vigo y del máster en Dirección Pública y Liderazgo institucional de esta misma universidad, además de otros dos másters. Ha trabajado en diferentes Administraciones autonómica y local, de la que es actualmente excedente. Docencia en universidades extranjeras de Europa y América, además de docencia vinculada a formación continua. Ponente en congresos de ámbito nacional e internacional. Docencia, investigación y publicaciones en gestión de recursos humanos, dirección pública, calidad en la Administración, negociación, y materias vinculadas a ciencia política, evaluación de políticas públicas o gestión de servicios públicos. Actualmente miembro y secretario del Grupo de Investigación del Observatorio para la gobernanza, de la Universidad de Vigo y de otros dos grupos de investigación.
\end{abstract}

\section{RESUMEN}

El presente artículo constituye un intento por abordar la evaluación de una política pública utilizando la metodología y su marco conceptual. Para ello, y desde el método científico de análisis, se ha revisado el nivel de ejecución o cumplimiento de objetivos de la política pública seguida en la Comunidad Autónoma de Galicia para la gestión del lobo ibérico en su interacción e impacto con la actividad humana. La razón última de este artículo estriba en operativizar el objetivo de desarrollo sostenible 16 de la Agenda 2030 de Naciones Unidas relativo al mantenimiento de la biodiversidad, utilizando para ello el análisis de políticas públicas, huyendo de tal manera del juicio o las opiniones y buscando el amparo del método científico plenamente validado. En su concreción se han revisado los objetivos gubernamentales autonómicos del gobierno gallego al respecto de la gestión de la especie del lobo ibérico -denominada «Plan del lobo de Galicia»-, así como las actuaciones realizadas y los objetivos conseguidos, en sus múltiples dimensiones de eficacia, eficiencia o impacto.

\section{PALABRAS CLAVE}

Lobo; evaluación; análisis de políticas públicas; agenda 2030; biodiversidad. 
GAPP. Nueva Época - N. ${ }^{0}$ 27, noviembre 2021 - ISSN: 1989-8991 - DOI: https://doi.org/10.24965/gapp.i27.10875 - [Págs. 115-130]

Gestión del territorio y biodiversidad en la agenda 2030: Evaluación de la política pública de gestión del lobo en su interacción ...

Oscar Briones Gamarra

\begin{abstract}
This article constitutes an attempt to approach the evaluation of a public policy using the methodology and concepts of public policy analysis. For this, and from the scientific method of analysis, the level of execution or fulfillment of objectives of the public policy followed in the Autonomous Community of Galicia for the management of the Iberian wolf in its interaction and impact with human activity has been reviewed. The ultimate reason for this article is to operationalize goal 16 of the 2030 agency regarding the maintenance of biodiversity, using the analysis of public policies, thus avoiding judgment or opinions and seeking the protection of the fully validated scientific method. In its concretion, the regional government objectives of the Galician government have been reviewed regarding the public policy of management of the Iberian wolf species -called «Plan del lobo de Galicia»-, the actions carried out and the objectives achieved, in its multiple dimensions effectiveness, efficiency or impact.
\end{abstract}

\title{
KEYWORDS
}

Lobo; evaluation; public policy analysis; agenda 2030; biodiversity.

\section{SUMARIO}

INTRODUCCIÓN. 1. LAAGENDA2030 Y SU IMPACTO REAL. 2. LAEVOLUCIÓN DELLOBO EN GALICIA COMOESTUDIODE CASO. 3. UNENFOQUEAL «PROBLEMADELLOBO» DESDE ELANÁLISISDE POLÍTICAS PÚBLICAS. 4. OBJETIVOS DE ACTUACIÓN. 5. PROBLEMAS DE IMPLEMENTACIÓN. 6. EVALUACIÓN DE LA POLÍTICA PÚBLICA DE LA GESTIÓN DEL LOBO EN GALICIA. 6.1. SITUACIÓN DE LA POBLACIÓN DEL LOBO EN GALICIA (INDICADOR DE EFICACIA). 6.2. GESTIÓN DE LA INTERACCIÓN CON EL SECTOR GANADERO (INDICADOR CUANTITATIVO Y CUALITATIVO). 3. INDICADORES DE FUTURO (INDICADOR DE EJEMPLIFICACIÓN). CONCLUSIONES.

«Un mundo en que el desarrollo y la aplicación de las tecnologías respeten el clima y la biodiversidad y sean resilientes; un mundo donde la humanidad viva en armonía con la naturaleza y se protejan la flora y fauna silvestres y otras especies de seres vivos».

Apartado: “Nuestra visión de futuro”. Agenda 2030.

\section{INTRODUCCIÓN}

El presente trabajo parte de entender que la preocupación por el clima, la biodiversidad y en general el sostenimiento medioambiental parece haber entrado decididamente en las agendas públicas y poco a poco en las preocupaciones prioritarias de los ciudadanos.

Sin embargo, fuera del rendimiento «antropocentrista» que obtenemos en el mantenimiento del clima, en definitiva, en garantizar la supervivencia de nuestra propia especie; se pretende acometer un tema que alude a quien verdaderamente no tiene voz alguna, básicamente porque aúlla, y porque en su aullido el oído humano no atisba a escuchar un lastimero grito de ayuda por la destrucción de hábitats y fauna.

Si bien el investigador ha de abstraerse, en la medida de lo posible, de sus preferencias personales, estas están siempre ahí; y lo que se pretende en este artículo no es esconderlas, sino engarzar esas preferencias personales con datos científicos y objetivos de gestión de políticas públicas y de percepción ciudadana al respecto, para avalar la necesidad acuciante de mejorar la gestión en general de los espacios naturales y la fauna salvaje.

Para dicho objetivo se utilizará en lo que no es sino una investigación exploratoria (ya que apenas existen trabajos similares) el análisis documental (legislación, programas, documentos estratégicos o acervo comunitario en la materia), principalmente centrado en fuentes primarias gubernamentales y del tercer sector que permitan diagnosticar el estado de la cuestión desde el enfoque de la evaluación de políticas públicas en esta especie de «era de la evaluación» (Dahler-Larsen, 2007, p. 93) en la que nos encontramos. Este concepto de evaluación, es abarcado desde multitud de definiciones, decantándonos por su sencillez ilustrativa por la que realiza la OCDE (2013): «... Apreciación sistemática y objetiva de un proyecto, programa o política en curso o concluido, de su diseño, su puesta en práctica y sus resultados. El objetivo es determinar la pertinencia y el logro de los objetivos, así como la eficiencia, la eficacia, el impacto y la sostenibilidad para el desarrollo». 
GAPP. Nueva Época - N. ${ }^{2}$ 27, noviembre 2021 - ISSN: 1989-8991 - DOI: https://doi.org/10.24965/gapp.i27.10875 - [Págs. 115-130]

Gestión del territorio y biodiversidad en la agenda 2030: Evaluación de la política pública de gestión del lobo en su interacción ...

Oscar Briones Gamarra

El objeto de estudio concreto, -gestión de la biodiversidad y espacios naturales- y en concreto la interacción del lobo con el ser humano, responde al hecho de constituir el del lobo un estudio de caso especialmente trascendente, pues su impacto y su interacción con la vida humana tiene casi inevitablemente consecuencias negativas en términos económicos, si bien difiere su conceptualización en términos sociales o medioambientales. Recordemos que no es lo mismo el precio que el valor.

Se opta además por la investigación basada en casos, en lugar de la clásica investigación basada en variables (Della Porta et al., 2013). Este tipo de investigación pretende realizar un examen detallado de un único ejemplo de una clase de fenómeno (Abercrombie et al., 1984) y pese a que esa definición convenía en que un estudio único no podría proporcionar información fiable sobre la generalidad estudiada; recientemente y cada vez con más énfasis, nos encontramos con el convencimiento de que un buen estudio de caso podría contribuir al desarrollo científico; en palabras de Flyvbjerg (2004, p 154): «... Uno puede generalizar sobre la base de un solo caso, y el estudio de un caso puede ser crucial para el desarrollo científico a través de la generalización como complemento o alternativa de otros métodos».

Por tanto, estudio de caso y técnicas de análisis de políticas públicas van de la mano en la metodología de este trabajo. Para dicho análisis, de finalidades explicativas y método inductivo (Fernández, 2005, p. 467) utilizaremos las herramientas propias del análisis de políticas públicas, en cuanto conjunto de instrumentos y técnicas para determinar la alternativa más adecuada para la resolución de un problema público (Boix, 1991). Fundamentalmente se utilizarán matrices para un análisis sistemático del problema, con la vista puesta en tener una buena definición del mismo, una panorámica detallada de los actores presentes, y una relación exhaustiva de las soluciones ya implementadas y las que están en estudio para su posible implementación. Todo ello desde el enfoque del análisis de políticas públicas, prestando atención a las fases de las políticas públicas, los diferentes actores y los estilos decisorios. No se ha de olvidar, en todo caso, que al analizar una política pública estamos analizando dos cuestiones: lo que los gobiernos deciden hacer pero también lo que deciden no hacer (Meny y Thoening, 1992, p. 10); y aquello que pueda mejorar la intervención objeto de la evaluación, la acción pública (Eusko Jaurlaritza-Gobierno Vasco, 2012).

Importante será también analizar específicamente la presencia de los actores gubernamentales, que precisamente nos permiten hablar del concepto de política pública; pero también analizar cuando un problema entra en la "caja negra eastoniana» y genera un proceso decisorio o una secuencia de resolución de un problema público. La capacidad de los gobiernos para resolver problemas públicos es, quizás más que nunca, una fuente principal de su propia legitimidad, y su eficacia resolutiva es una cuestión sobresaliente de toda política gubernamental (Lindblom, 1991).

Cabe no olvidar tampoco, que las políticas medioambientales han aparecido hace relativamente poco en las carteras de servicios de los estados, al hilo de la ampliación del campo de acción de las esferas gubernamentales. En concreto, la gestión de la fauna y su interacción con el ser humano era hasta hace bien poco un tema de autoregulación social, en el que normalmente el ser humano, como actor predominante, vencía en esa interacción llevando, en el caso que nos ocupa al lobo, a los límites de su extinción.

Junto a la disciplina técnica del análisis de políticas públicas, este trabajo se ampara a nivel político y legal en la Agenda 2030, a la que pretende contribuir desde un estudio de caso concreto, cercano y fundamentado técnica y científicamente. Su impacto es mayor dada la escasa presencia del trabajo de los analistas de políticas públicas en España, en donde la Administración sigue dominada por una arraigada tradición juridicista (Fernández, 2005). La elección del ecosistema de Galicia responde al hecho de que es una de las zonas de mayor población lobera de España y en la que el lobo se entremezcla con una dispersión de núcleos de población sin igual en el resto de España, por lo que los conflictos entre el lobo y el ser humano son especialmente frecuentes.

\section{LA AGENDA 2030 Y SU IMPACTO REAL}

El año 2015 es considerado como un punto inflexión en la génesis de la Agenda 2030. En concreto, el Acuerdo de París (2015) con la aprobación de la resolución A/RES/70/1 de la Asamblea General de Naciones Unidas titulada Transformar nuestro mundo: la Agenda 2030 para el Desarrollo Sostenible constituye el inicio del entorno jurídico-político en el que se pretende enmarcar el presente estudio.

En dicho documento de inicio de la Agenda 2030, se establece «... observando la importancia de garantizar la integridad de todos los ecosistemas, incluidos los océanos, y la protección de la biodiversidad». 
GAPP. Nueva Época - N. ${ }^{0}$ 27, noviembre 2021 - ISSN: 1989-8991 - DOI: https://doi.org/10.24965/gapp.i27.10875 - [Págs. 115-130]

Gestión del territorio y biodiversidad en la agenda 2030: Evaluación de la política pública de gestión del lobo en su interacción ...

Oscar Briones Gamarra

Siguiendo así la senda del Convenio Internacional sobre Diversidad Biológica (CBD, 1992), del que España forma parte desde 1993 y que se considera la norma de mayor relevancia internacional respecto a la biodiversidad.

En la resolución A/RES/70/1 de la Asamblea General de Naciones Unidas, las partes reconocen que la labor de adaptación debería llevarse a cabo entre otros aspectos teniendo en cuenta los ecosistemas vulnerables, y ello desde una óptica científica, para convencer desde los datos más que desde el voluntarismo o las concepciones propias. Se establece literalmente que «... dicha labor debería basarse e inspirarse en la mejor información científica disponible y, cuando corresponda, en los conocimientos tradicionales, los conocimientos de los pueblos indígenas y los sistemas de conocimientos locales, con miras a integrar la adaptación en las políticas y medidas socioeconómicas y ambientales pertinentes, cuando sea el caso».

Se recurre por tanto a criterios científicos y empíricos, pero también, en línea con la gobernanza, a la participación de una especie de «saber popular» para ayudar a gestionar la interacción entre la biodiversidad y las comunidades humanas, precisamente uno de los focos de atención de este trabajo.

En concreto, la agenda 2030 establece 17 Objetivos de Desarrollo Sostenible y un total de 169 metas específicas. Específicamente, el objetivo del que tratamos (llamados comúnmente y de aquí en adelante ODS) en este trabajo, es el objetivo 15 que establece:

«Proteger, restablecer y promover el uso sostenible de los ecosistemas terrestres, gestionar sosteniblemente los bosques, luchar contra la desertificación, detener e invertir la degradación de las tierras y detener la pérdida de biodiversidad».

De forma resumida aunque en la nota al pie se incorporan algunos elementos relevantes del ODS $15^{1}$; sus líneas maestras pasan por la conservación de ecosistemas naturales, la gestión sostenible de los recursos naturales deteniendo inmediatamente la destrucción de hábitats y en particular de los bosques, o la protección a la fauna y la biodiversidad en general, defendiéndola de «agentes agresores» como la caza furtiva, la presión urbanizadora o el tráfico ilegal de especies.

No es baladí el hecho de que la filosofía proteccionista es más factible y «cómoda» desde los países ricos y con pocos problemas de superpoblación. Por ello también el objetivo 15 hace referencia al rasgo de la pobreza, dando a entender que el proteccionismo tiene concomitancias en función de la existencia o no de problemas sociales y económicos de importancia. Este es precisamente uno de los debates de fondo de mayor calado al abordar las políticas de protección, conciliar el desarrollo económico y social de los países pobres con una mayor protección medioambiental cuando los medios del país son más limitados. Este hecho enlaza con la prescripción de la Agenda 2030 al respecto de «movilizar y aumentar significativamente los recursos procedentes de todas las fuentes para conservar y utilizar de forma sostenible la biodiversidad y los ecosistemas»; o «... Movilizar recursos considerables de todas las fuentes y a todos los niveles para financiar la gestión forestal sostenible y proporcionar incentivos adecuados a los países en desarrollo para que promuevan dicha gestión, en particular con miras a la conservación y la reforestación»; aumentando -cabe no olvidarlo- la capacidad de las comunidades locales para perseguir oportunidades de subsistencia sostenibles.

Hasta aquí se ha presentado una mera descripción de principios que incluye la agenda 2030 relacionados con la protección del territorio y la fauna. Trasladando ya el enfoque al impacto real de la Agenda, parece necesario comenzar a utilizar las categorías técnicas del análisis de políticas públicas.

Para empezar el concepto de «entrada en la agenda» parece consolidado en las agendas públicas para el caso del medioambiente. El nivel de sensibilización es bastante aceptable independientemente del

15.1 De aquí a 2020, asegurar la conservación, el restablecimiento y el uso sostenible de los ecosistemas terrestres y los ecosistemas interiores de agua dulce y sus servicios, en particular los bosques, los humedales, las montañas y las zonas áridas, en consonancia con las obligaciones contraídas en virtud de acuerdos internacionales.

15.2 De aquí a 2020, promover la puesta en práctica de la gestión sostenible de todos los tipos de bosques, detener la deforestación, recuperar los bosques degradados y aumentar considerablemente la forestación y la reforestación a nivel mundial.

15.5 Adoptar medidas urgentes y significativas para reducir la degradación de los hábitats naturales, detener la pérdida de biodiversidad y, de aquí a 2020, proteger las especies amenazadas y evitar su extinción.

15.7 Adoptar medidas urgentes para poner fin a la caza furtiva y el tráfico de especies protegidas de flora y fauna y abordar tanto la demanda como la oferta de productos ilegales de flora y fauna silvestres.

15.8 De aquí a 2020, adoptar medidas para prevenir la introducción de especies exóticas invasoras y reducir significativamente sus efectos en los ecosistemas terrestres y acuáticos y controlar o erradicar las especies prioritarias.

15.9 De aquí a 2020, integrar los valores de los ecosistemas y la biodiversidad en la planificación, los procesos de desarrollo, las estrategias de reducción de la pobreza y la contabilidad nacionales y locales. 
GAPP. Nueva Época - N. ${ }^{0}$ 27, noviembre 2021 - ISSN: 1989-8991 - DOI: https://doi.org/10.24965/gapp.i27.10875 - [Págs. 115-130]

Gestión del territorio y biodiversidad en la agenda 2030: Evaluación de la política pública de gestión del lobo en su interacción ...

Oscar Briones Gamarra

color del partido político que gobierne, y analizando el gasto público en políticas medioambientales parece haberse consolidado esta protección medioambiental como una prioridad gubernamental, pero también social de la ciudadanía, que se sitúa mayoritariamente en posiciones de preocupación por el medio ambiente (CIS, 2010).

El caso propuesto aquí, sin embargo, enfrenta directamente intereses económicos y humanos con intereses medioambientales (protección de una especie como el lobo) y lleva a una situación de estrés importante el equilibrio entre protección del valor medioambiental y protección del valor economía. En otras palabras, se detecta un cierto consenso social sobre la protección del medio ambiente, pero este consenso se rompe cuando interacciona con situaciones de merma económica (imposibilidad de construir en terrenos naturales, imposibilidad de cazar o pescar en determinados territorios, limitaciones de acceso para la protección de la fauna, o desde luego en el caso que nos ocupa como caso práctico, la contraposición de intereses entre el valor económico de las ganaderías y el valor «social» de la preservación de la fauna y en concreto del lobo).

En esas situaciones, la balanza entre economía y desarrollo económico y medioambiente sigue rompiéndose en beneficio del primero, y ello aun cuando puede afirmarse que el respeto al medio ambiente ha entrado y se ha consolidado en las agendas públicas.

Las premuras electorales, el hecho objetivo de que «los animales no votan», de que la defensa de los animales tiene una menor fortaleza que la defensa organizada y legitimada de los sectores económicos, es una variable a tener muy en cuenta. También, como se verá, es una variable determinante la socialización en valores medioambientales que presente cada país, y a ese respecto nos dedicaremos en las páginas siguientes a analizar dicha variable en el caso español y gallego.

\section{LA EVOLUCIÓN DEL LOBO EN GALICIA COMO ESTUDIO DE CASO}

En este apartado se inicia el enfoque de estudio de caso, con la idea de proyectar desde un caso concreto como el de la gestión del lobo en Galicia, problemáticas y métodos de solución que se pueden estar dando ante problemas similares en distintos territorios, aunque por supuesto cualquier extrapolación pasaría por un estudio profundo de las circunstancias del entorno socioeconómico y medioambiental concreto al que se pretenden extrapolar dichas soluciones.

Específicamente se parte, de la evaluación de la política pública al respecto de la gestión del lobo en Galicia, entendiendo que esta reúne las características fundamentales para ser considerada una política pública, señaladas por Aguilar (2008). Esta acción pública, denominada «Plan de gestión del lobo en Galicia» (en adelante PGLG) ${ }^{2}$ se inicia con un gobierno de distinto color político (bipartito partido socialista y bloque nacionalista galego) al que desde octubre de 2009 hasta 2024 (si agotara la legislatura) está gobernando (partido popular).

Para acotar convenientemente el objeto de estudio, cabe señalar que se estaría tratando de una competencia exclusiva de la Comunidad Autónoma de Galicia, «... dictar normas adicionales sobre protección del medio ambiente» (Artículo 27.30 del Estatuto de Autonomía de Galicia) que se ha desarrollado normativamente en la ley autonómica 9/2001 de conservación de la naturaleza.

Se parte así, como se puede constatar en el preámbulo del PGLG, de la consideración de que la población de lobos de Galicia puede ser objeto de medidas de gestión ${ }^{3}$ siendo declarada anteriormente, en el Decreto 284/2001, de 11 de octubre, por el que se aprueba el Reglamento de caza de Galicia, «especie cazable», si bien la realidad es que su caza se ha venido realizando bajo autorización administrativa específica una vez constatada la existencia de daños y supuestamente «... con plenas garantías de conservación de la población de esta especie».

Según el PGLG, los estudios realizados entre los años 1999 y 2003 en el ámbito autonómico determinaron que la presencia del lobo en Galicia es amplia, ocupando la mayor parte del territorio autonómico

\footnotetext{
2 Publicado en el Diario Oficial de Galicia del 20 de enero de 2009; Decreto 297/2008.

3 Dado que está incluida en el anexo VI (especies animales y vegetales de interés comunitario cuya recogida en la naturaleza y explotación pueden ser objeto de medidas de gestión) de la Ley 42/2007, de 13 de diciembre, del patrimonio natural y de la biodiversidad, que traspone al ordenamiento jurídico español la Directiva 92/43/CEE del Consejo, de 21 de mayo, relativa a la conservación de los hábitats naturales y de la flora y fauna silvestres. El Plan de gestión del lobo en Galicia que se aprueba con el presente decreto pretende poner fin a las carencias anteriormente señaladas, dando cumplimiento, además, a las recomendaciones del Comité Permanente del Consejo de Berna respecto a la necesidad de gestionar a la especie de acuerdo con un plan de manejo y a la Estrategia para la conservación y gestión del lobo en España, aprobada en Conferencia sectorial el 29 de enero de 2005.
} 
GAPP. Nueva Época - N. ${ }^{\circ}$ 27, noviembre 2021 - ISSN: 1989-8991 - DOI: https://doi.org/10.24965/gapp.i27.10875 - [Págs. 115-130]

Gestión del territorio y biodiversidad en la agenda 2030: Evaluación de la política pública de gestión del lobo en su interacción ...

Oscar Briones Gamarra

y estando presente incluso en zonas muy humanizadas; constatándose la existencia de una población de lobos continua y «abundante» a tenor del gobierno autonómico (Xunta, 2020) a lo largo de su área de distribución.

El marco normativo en el que se ha de desarrollar esta política pública y su acción concreta en la protección de una especie como el lobo, dimana en cuanto a su jerarquía normativa, de la legislación comunitaria europea, su traslación nacional a la legislación española común a todo el estado y el desarrollo legislativo y competencial que se en el nivel regional o autonómico desde la Comunidad Autónoma de Galicia.

\section{ImAgen 1. Hitos Legislativos PRincipales de los Últimos Veinte años en LA gestión del Lobo en GALICIA}

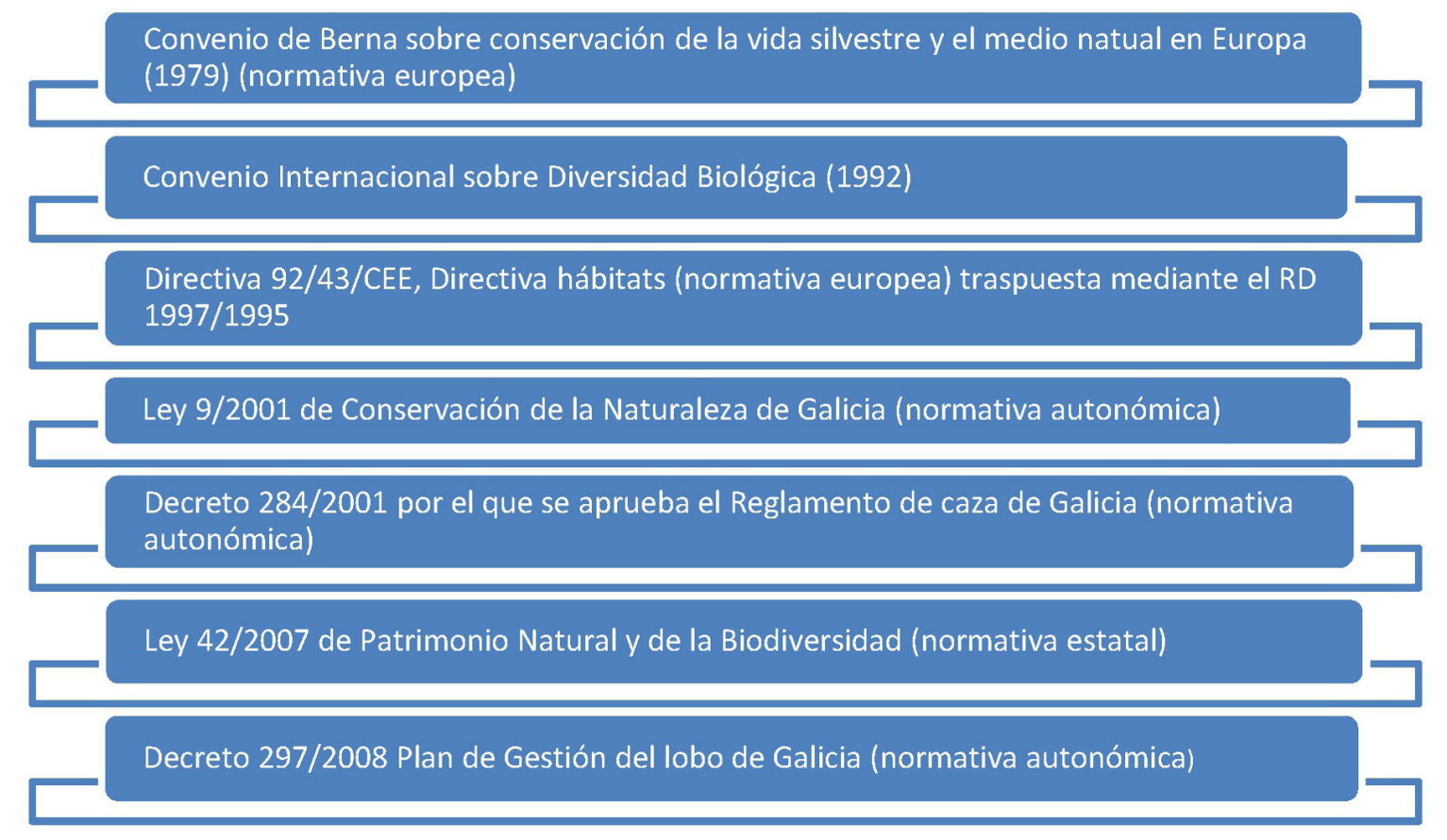

Fuente: Elaboración propia a partir de revisión legislativa integral.

\section{UN ENFOQUE AL «PROBLEMA DEL LOBO» DESDE EL ANÁLISIS DE POLÍTICAS PÚBLICAS}

Es muy revelador, en la fase de descripción del problema, que el propio «Plan de gestión del lobo de Galicia» incluya un punto 3 denominado «conflictividad», lo que introduce un factor de definición del lobo como un problema para la convivencia humana.

El citado plan se marca como objetivo tratar de reducir tanto la carga económica como el conflicto social generado hasta ese momento por el pago de indemnizaciones ante las pérdidas que el lobo generaba en las ganaderías. En concreto la orden del PGLG en su propia exposición de motivos destaca que «... la presencia del lobo en espacios rurales muy humanizados es, con frecuencia, causa de conflicto con los ganaderos» (Xunta, 2015).

Comenzando por la fase clásica de las políticas públicas de «definición o surgimiento del problema», lo revelador es que la propia administración parece realizar una «definición del problema» exclusivamente como un problema para los humanos (no como un problema de recursos naturales limitados). En este sentido cabe recordar, de una manera muy elemental, que en el análisis de políticas públicas no existen los problemas objetivos en sí, sino distintas definiciones de un problema que constituye una fase crucial (Subirats, 2001, p. 260); y que, de hecho, los distintos actores pugnan por introducir una definición determinada del problema -los ecologistas como un problema de preservación de una especie, los ganaderos como problema económico, habitantes que lo teman como un problema de seguridad en sus domicilios, cazadores porque compite por sus mismas presas, etc.- (Tamayo, 1997, p. 286). En definitiva, como afirma Subirats 
GAPP. Nueva Época - N. ${ }^{0}$ 27, noviembre 2021 - ISSN: 1989-8991 - DOI: https://doi.org/10.24965/gapp.i27.10875 - [Págs. 115-130]

Gestión del territorio y biodiversidad en la agenda 2030: Evaluación de la política pública de gestión del lobo en su interacción ...

Oscar Briones Gamarra

(2001, p. 260) los actores se movilizan según sus preferencias e intereses; intentando influir, condicionar, bloquear o activar las decisiones públicas utilizando todo tipo de recursos.

Respecto a cómo consiguen los problemas entrar en la agenda, se puede afirmar que el lobo ha entrado en la agenda pública impulsado por el impacto mediático de los avistamientos de lobos en cercanías de núcleos urbanos ${ }^{4}$ o por ataques a la ganadería, facilitado por el sesgo cultural derivado en una concepción «diabólica» sobre el lobo ${ }^{5}$. Junto a esta accesibilidad a la agenda tan afectada por lo que Tamayo (1997, p. 290) denomina sesgo en la accesibilidad; estamos ante tema, en su contraparte, en el que los actores del tercer sector (movimientos ecologistas) intentan introducir en la agenda una visión o definición del problema en cuanto a necesaria protección de la especie para evitar su extinción y mantener la biodiversidad preceptuada por la Agenda 2030 y la CBD (1992). Además, se ha constatado la máxima de la disciplina del análisis de políticas públicas de que los problemas tienden a entrar por familias, y junto a los daños del lobo se han introducido otros problemas de interacción con la fauna, relacionados con el fenómeno de la «defaunación» (Galetti y Dirzo, 2013) como los destrozos agrícolas del jabalí, o los daños patrimoniales en vehículos por el atropello de fauna salvaje. El lobo entra precisamente en el concepto de "defaunación», relacionado con grandes vertebrados que generan más daños a los humanos y que desembocan en lo que se ha denominado "bosque vacío» en que se conserva el espacio natural vegetal pero libre de especies «dañinas» (normalmente de gran tamaño) desde un punto de vista antropocentrista radical (el lobo, el lince, el jabalí, el tigre en la india o el jaguar en américa latina pueden ser ejemplos de esta problemática).

Cada vez con mayor énfasis desde este tipo de análisis se recomienda tener muy presentes los grupos de intereses y/o de influencia que conviven en cada «arena» de la política pública (Lowi, 1964) (grupos de poder, grupos de presión, asociaciones y ong's, grupos de comunicación, opinadores cualificados, expertos, etc.). Se trata de actores que también participan en las políticas públicas y cada vez con mayor influencia dada la extensión de las redes sociales y las plataformas públicas de participación, así como por el entorno de gobernanza en el que se mueven las administraciones públicas actuales. A mayor capacidad de influir y presentar demandas de los actores en cuestión, mayor será la cuota de temas a incorporar a la agenda (Tamayo, 1997, p. 290).

Para organizar mejor los actores presentes, algunos mencionados de forma somera anteriormente, la disciplina del análisis de políticas públicas recomienda la utilización del instrumento de las matrices de análisis de los actores presentes, que, en nuestro caso concreto, presenta la siguiente apariencia:

TABLA 1. ACtORES PRESENTES Y DEFINICIÓN DEL PROBLEMA

\begin{tabular}{cc}
\hline ACTORES PRESENTES & DEFINICIÓN DEL PROBLEMA DEL LOBO \\
\hline GANADEROS & AMENAZA \\
\hline CAZADORES & AMENAZA \\
\hline ECOLOGISTAS & PRESERVACIÓN \\
\hline HABITANTES DEL MEDIO RURAL & SEGURIDAD PERSONAL \\
\hline CIUDADANÍA GENERAL & AMENAZA/PRESERVACIÓN \\
\hline GOBIERNO AUTONÓMICO & PROBLEMA/PRESERVACIÓN
\end{tabular}

Fuente: Elaboración propia a partir de datos del Plan de gestión del lobo en Galicia.

\footnotetext{
4 En los últimos tiempos las noticias sobre lobos paseando por las playas en Xove, o por pistas forestales a plena luz del día en parques naturales como el de Os Ancares, han sido muy frecuentes con una cierta inclinación a la creación de alarma social a nuestro entender. De hecho, podríamos preguntarnos si la noticia es que el lobo nos invade-como se pretende divulgar-o que se abren tantas pistas forestales que la fauna no tiene más remedio que transitar por ellas, a pesar de la existencia de los llamados «pasos de fauna». De nuevo la definición de un problema o de lo que es o no noticia.

5 Según se extrae del informe del Grupo de Trabajo del lobo (2005), el lobo tiene también un enorme peso cultural y genera gran cantidad de mitos, lo que puede enturbiar la comprensión de su historia natural por parte del gran público. Hasta hace pocas décadas, el lobo encarnaba el símbolo de la maldad, pero en los últimos años representa símbolos opuestos para distintos sectores sociales. Para el público urbano, simboliza la naturaleza salvaje y perseguida, pero continúa representando un símbolo diabólico para muchos sectores rurales.
} 
GAPP. Nueva Época - N. ${ }^{2}$ 27, noviembre 2021 - ISSN: 1989-8991 - DOI: https://doi.org/10.24965/gapp.i27.10875 - [Págs. 115-130]

Gestión del territorio y biodiversidad en la agenda 2030: Evaluación de la política pública de gestión del lobo en su interacción ...

Oscar Briones Gamarra

\section{OBJETIVOS DE ACTUACIÓN}

Se acomete este apartado analizando las declaraciones oficiales de objetivos de actuación establecidos por el gobierno autonómico, materiales que se encuentran básicamente en documentos de planificación, presupuestación o memorias de actividad de la Administración.

De forma directa, la normativa autonómica analizada hace mención a la fase de formulación de alternativas en la cual, al criterio del gobierno se suman las aportaciones de científicos, ecologistas o sectores económicos afectados (fundamentalmente el sector ganadero). Se ha seguido así la «lógica de la conjetura», relatada por Dunn (1994) según la cual se formulan posibles soluciones provenientes del juicio de los expertos, basadas en argumentos científicos y soportadas también en buena medida por una intuición de personas cualificadas. En todo caso no se aprecia, a la contra, un alto desarrollo científico para soportar argumentalmente las líneas de actuación a seguir, quizás en la línea de que la ciencia es importante, pero lo es más la persuasión y la negociación con los actores implicados sobre la solución a tomar, como estableció Lindblom (1991).

Sucedida esta escueta fase técnica y gubernamental de formulación de alternativas para encontrar posibles soluciones, el gobierno autonómico gallego establece una serie de objetivos con la vista puesta en conseguir «... garantizar la viabilidad de esta especie» (Punto 4 PGLG) pero haciendo esta viabilidad compatible con la existencia de la ganadería y la rentabilidad económica de las explotaciones agropecuarias, utilizando para ello las ayudas económicas que se establezcan para resarcir a los ganaderos de los daños del lobo.

Se aprecian así dos líneas maestras de actuación como la:

- Viabilidad de la especie, también en tanto que exponente de biodiversidad y equilibrio biológico (Xunta, 2020).

- Compatibilidad con la actividad de ganadería.

Llama la atención, de entrada, la falta de mención a la destrucción del territorio y la urbanización abusiva como elemento determinante, lo que nos lleva a pensar otra de las máximas del análisis de políticas públicas como es el no buscar soluciones a problemas de difícil o imposible solución o a los que no se ven soluciones factibles políticamente. El problema coste-beneficio de poner límites a la urbanización intensiva del territorio o la ampliación de zonas protegidas o reservas naturales, supera a los políticos que prefieren obviar esta estrategia substituyéndola por otras más gestionables -aunque de menor impacto final- como la compensación económica a ganaderos o el control estricto de la posibilidad de la caza del lobo.

Cabe recordar en este punto que, como se establece en el análisis de políticas públicas, la mejor solución para el político es aquella que goza de mayor «factibilidad» o viabilidad, es decir, escoger la mejor alternativa, pero teniendo presentes los costes sociales. La estructura social y económica de dos instituciones jurídicas como la propiedad y la herencia es particularmente compleja y dispersa en Galicia como para implementar soluciones de protección del territorio natural, que serían de un enorme coste político, aunque sí de gran impacto si el valor a proteger es la naturaleza.

De forma detallada entre los objetivos del Plan de gestión del Lobo se incluyen (Punto 5 PGLG): medidas de coexistencia del lobo con el ser humano, estabilización de poblaciones loberas, minimizar y compensar económicamente por pérdidas causadas por el lobo, puesta en valor económico del lobo como recurso económico relacionado con la naturaleza y el turismo sostenible, o programas de sensibilización y establecimiento de sistemas de participación social para que todos los sectores puedan aportar en el diseño de la política de gestión del lobo.

Adaptando las soluciones ofrecidas a la teoría del análisis de políticas públicas, se identifican, en el caso analizado, los rasgos básicos del modelo «salir del paso» establecido en los desarrollos teóricos por Lindblom (1959) o March y Olsen (1972), en sus trabajos seminales en los que se establece como predominante un modelo de toma de decisiones basada en el compromiso, la negociación y la presión entre actores que son interdependientes unos de otros.

Por otra parte, se identifica una política pública regulativa en el sentido definido por Subirats et al. (2008), con los costes concentrados (indemnizaciones a ganaderos y restricciones a la caza) pero con los beneficios difusos (el supuesto interés general de mantener una especie como el lobo y por extensión un alto nivel de biodiversidad como reconoce la propia Xunta de Galicia (2020). 
GAPP. Nueva Época - N. ${ }^{2}$ 27, noviembre 2021 - ISSN: 1989-8991 - DOI: https://doi.org/10.24965/gapp.i27.10875 - [Págs. 115-130]

Gestión del territorio y biodiversidad en la agenda 2030: Evaluación de la política pública de gestión del lobo en su interacción ...

Oscar Briones Gamarra

\section{PROBLEMAS DE IMPLEMENTACIÓN}

Tradicionalmente es una fase infravalorada del ciclo de vida de una política pública, como han estudiado excelsamente Pressman y Wildasky (1984). La implementación de políticas públicas representa el momento en que se ha decido una solución a un problema público y comienzan a detectarse problemas en la implementación de dicha solución, en definitiva problemas a la hora de poner en marcha la solución pública seleccionada. En numerosas ocasiones esta fase es la causa velada del fracaso de una política pública. Se trata, en este punto de la investigación, de analizar el conjunto de procesos que, tras la fase de programación, tienden a la realización concreta de los objetivos de una política pública, y por lo tanto estamos ante una perspectiva de eficacia (Subirats et al., 2008).

La fase de implementación es básica, ya que la Administración Pública, en contra de lo que defendía Max Weber (1972) no es un mero «brazo ejecutor» de las políticas públicas. Muy al contrario, es necesario tener en cuenta los problemas de implementación que pueden aparecer en torno a una política pública, que en el caso estudiado pueden hacer mención a problemas genéricos de organización administrativa (Ballart, 1993, p. 201), a las posibilidades de inspección (por ejemplo las plantillas destinadas a la vigilancia de la caza furtiva), a problemas burocráticos (quejas sobre la eficacia y la agilidad en el pago de las indemnizaciones al ataque del lobo), al carácter coercitivo e intensidad de las sanciones impuestas, al control de elementos agresores como la urbanización ilegal y dispersión ilegal de núcleos poblacionales, los atropellos o la falta de pasos de fauna, entre otros. También el clima social o de opinión, así como el momento del ciclo económico son fundamentales a la hora de diseñar bien la implementación de una política pública.

Es esencial además, analizar la interacción entre actores públicos y privados, en el caso propuesto es necesario analizar la interacción entre el actor gubernamental y los dos actores principales: los ganaderos y constructores por un lado (prevalencia del interés económico) y los grupos ecologistas por otro (prevalencia del interés de preservación). Como ha señalado Bardach (2001), para mejorar la implementación el ejecutor deberá prever las resistencias y contar con los apoyos y la capacidad, destreza y legitimación suficiente entre los actores para llegar a buen término.

El esquema que se puede observar en el caso concreto de Galicia, cumple con la idea de participación de la sociedad civil en la elaboración de las políticas públicas, si bien esta participación parece ser más formal que real, manteniendo el actor gubernamental su posición de fuerza (actor preeminente) tanto a la hora de legislar como a la hora de implementar la política pública.

El enfoque de la acción pública implementada en el caso de Galicia, implica una orientación «top-down» (Meny y Thoening, 1992), desde el momento en que el gubernamental es el actor claramente predominante, valiéndose de la administración como órgano de ejecución. Como se ha venido defendiendo se ha cumplido el expediente del «barniz» de participación social y sí es cierto que los actores de la sociedad civil han participado tibiamente en el diseño de la política pública.

También el enfoque «multinivel» tan complejo en España por el número de Administraciones Públicas implicadas ha de ser tenido en cuenta en este punto como recuerda (Fernández, 2005, p. 276) con su concepto de colaboración interinstitucional. Para el caso concreto, y aun siendo predominante el gobierno autonómico que es quien tiene la competencia principal, no es menos cierto que es imprescindible conocer cómo se relacionan las distintas Administraciones con competencias en el sector (Rojo y Varela, 2013) para entender este tipo de políticas públicas; relaciones entre las que destacan sobremanera, la colaboración de la Administración del Estado y las Administraciones Autonómicas, a las que se unen -en un rango de menor capacidad competencial- las Administraciones Locales.

Si la acción pública escogida tras analizar la política pública a seguir no se cumple, lo será por una suerte de factores como el no conocer bien la decisión o que los sistemas de control-sanciones y recompensas de los implementadores- no funcionen debidamente.

De esta manera, los criterios de evaluación de la calidad de la implementación de la política pública están marcados por la conformidad legal del proceso de implementación y la eficacia en cuanto a la realización de los objetivos formales marcados en la planificación de la política pública.

En todo caso, debe señalarse que en la política concreta de gestión del lobo realizada por la Xunta de Galicia, no se han detectado a lo largo de la investigación, grandes problemas en la fase de implementación, atisbándose que las cuestiones principales sobre el éxito o el fracaso de la política se situarán en aspectos como la selección de objetivos concretos, alternativas a implementar o la propia definición original del problema público a resolver. 


\section{EVALUACIÓN DE LA POLÍTICA PÚBLICA DE LA GESTIÓN DEL LOBO EN GALICIA}

Se despliega ahora un método de investigación sistemático sobre la configuración de un programa o política determinado, su implementación y efectividad; y si bien a lo largo de este artículo se ha desarrollado una perspectiva cíclica del análisis de políticas públicas, se cerrará el foco en este apartado estrictamente sobre la fase de evaluación, intentando, como recuerda Ballart (1993, p. 203), aislar la intervención pública de otros factores causales.

De entrada, cabe señalar que se está empleando un método científico, no juicios de valor; y además el momento de la evaluación escogido es el clásico de la evaluación de resultados, si bien hay que recordar que existe una amplia tipología de evaluaciones como las de proceso, diseño, o implementación -entre otras- y que además se aplican en momentos distintos, bien incluso antes de la puesta en marcha del programa o política pública, durante el desarrollo del mismo, o a su finalización.

En el caso analizado, se ha optado por una evaluación externa y «ex-post» de los resultados obtenidos en función de los objetivos de actuación que se habían marcado y que han sido comentados anteriormente. Los objetivos de este tipo de evaluación, más habitual en países con menor «cultura de evaluación» (DahlerLarsen, 2007, p. 95), se centran en mostrar para la investigación científica en curso, hasta qué punto las medidas de actuación propuestas por el gobierno pueden ser útiles (en nuestro caso para el mantenimiento de una especie concreta y, por extensión, para el cumplimiento del objetivo de mantenimiento de la biodiversidad establecido en la agenda 2030). Es una metodología de evaluación de eficacia fundamentalmente denominada «de balance» Subirats (2001), «de resultados» o «sumativa»; y su objeto suele ser el de recoger información sobre los resultados finales del programa y facilitar así un juicio de valor global sobre el mismo, ofreciendo de esta manera un resultado recapitulativo de actuación una vez que esta ha finalizado. La evaluación ha de proporcionar una base de comparación que permita objetivizar la valoración sobre la eficacia de la política o sobre la adecuación entre la política implementada y el cumplimiento de los objetivos marcados (Ballart, 1993, p. 201); en el caso que nos ocupa midiendo la viabilidad de las poblaciones del lobo así como la satisfacción del sector ganadero y el impacto de las medidas de compensación. Fundamentalmente se realiza un baremo del contraste entre los resultados obtenidos y los objetivos de partida del programa, permitiendo proporcionar la suficiente información para una labor evaluadora-juzgadora en el sentido de Rossi-Freeman (1985, p. 372).

Se intenta también así cubrir un «gap» de la gestión pública en España (Subirats, 2001), como es la escasa presencia de mecanismos como los «sunset legislation» (condicionamiento de la continuación de un programa a la demostración de eficacia) o «legislative oversight» (vigilancia legislativa del cumplimiento), que sí existen en otros países y que permiten la actuación del poder legislativo en el control de la continuidad o la implementación de un programa.

Con estas bases teóricas de partida, sobre la evaluación «ex-post» que se intenta desplegar, se han establecido algunos indicadores de evaluación de la política pública analizada:

\subsection{Situación de la población del lobo en Galicia (Indicador de eficacia)}

Fundamentalmente desde la información extraída de diferentes censos nacionales de la especie, en concreto dos grandes estudios a nivel del territorio español, haciendo valer la necesidad de usar datos válidos (Ballart, 1993, p. 205), legitimados y a la vez sencillos y con información clara que pueda también entender la población en general.

Esta última cuestión nos llevará a plantear la oportunidad de hacer una utilización intensiva de los datos que ya recoge de forma ordinaria y continuada la Administración (Ballart, 1993, p. 206), pues cada cierto tiempo las distintas administraciones van actualizando los datos al respecto.

La referencia inicial de los datos parte del período entre 1986 y 1988, en el que por encargo del entonces Instituto para la Conservación de la Naturaleza (ICONA), se llevó a cabo el «primer estudio nacional» para evaluar la distribución, la situación y la problemática del lobo en España. Posteriormente hemos utilizado los datos censales de los años 1995-2000, la información a nivel autonómico de Llaneza en la primera década del año 2000 y el segundo censo nacional de la especie, cuyos trabajos de campo han sido realizados por las comunidades autónomas entre 2012 y 2014 (MAGRAMA, 2016). A mayores se ha cruzado la información disponible con la proporcionada por la propia Consejería de Medio Ambiente, Territorio y Vivienda que publicó su último censo del lobo ibérico en Galicia con un resumen de los años 2013-2015 (Xunta de Galicia, 2017). Cabe hacer mención, no obstante, a que la forma de recolección de los datos, y en concreto el 
GAPP. Nueva Época - N. ${ }^{0}$ 27, noviembre 2021 - ISSN: 1989-8991 - DOI: https://doi.org/10.24965/gapp.i27.10875 - [Págs. 115-130]

Gestión del territorio y biodiversidad en la agenda 2030: Evaluación de la política pública de gestión del lobo en su interacción ...

Oscar Briones Gamarra

método de estimación de las poblaciones loberas en las Comunidades Autónomas, ha sido puesto en duda frecuentemente por organizaciones ecologistas ${ }^{6}$.

De manera general se puede afirmar con datos contrastados que las manadas de lobos se mantienen estables, con leves aumentos en términos generales (Xunta, 2017, p. 8), y que las políticas de compensación económica y preservación están cumpliendo su cometido.

Sin embargo, como se analizará más adelante, la depredación del territorio, la urbanización intensiva (más acusada en el litoral con la presión de las segundas residencias) y por tanto la reclusión del lobo y en general la fauna silvestre a zonas con menor presencia humana, siguen siendo el factor determinante de agresión a la especie y a la fauna silvestre en general. Los propios mapas de extensión del lobo (Xunta, 2017) ofrecen una panorámica en la que su presencia es incompatible en la franja costera atlántica en la que la presión por urbanizar y el turismo han acabado con las escasas posibilidades que el lobo y otras especies silvestres albergaban de prosperar.

La destrucción de hábitats naturales sigue siendo un factor determinante, que encaja a la perfección en lo que en políticas públicas se ha denominado las «políticas públicas de no hacer». Esto es, como no se puede frenar la urbanización intensiva, se reorienta la política pública -a costa de la efectividad- hacia factores más «políticamente manejables» como puedan ser el freno a la caza o la compensación económica a los ganaderos. El verdadero problema por resolver, la depredación del territorio por el ser humano, no tiene políticamente una buena solución y directamente los esfuerzos de los gobiernos se centran en que dicho problema no entre en la agenda.

\section{Gráfica 1. Población del lobo en Galicia (en manadas)}

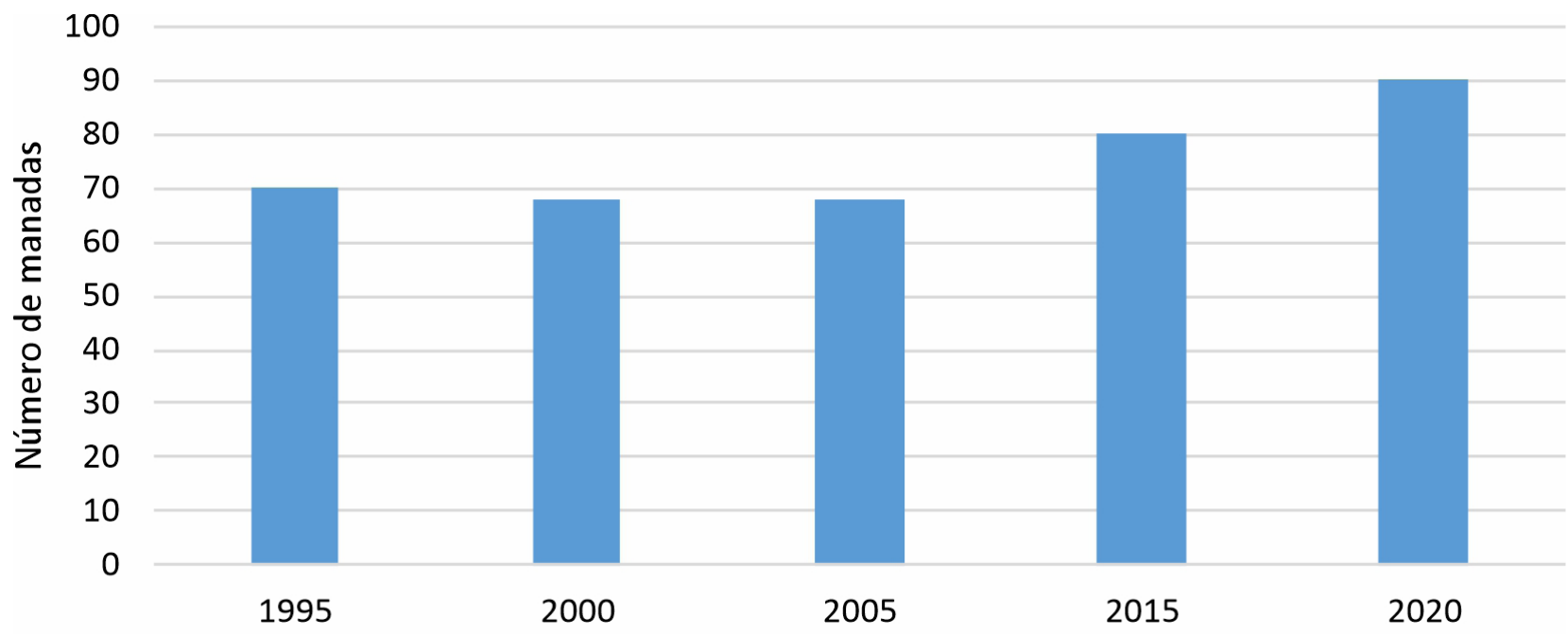

Años de sondeo

Fuente: Elaboración propia a partir de datos actualizados del Ministerio de Medio Ambiente y Consellería de Medio Ambiente, Territorio y Vivienda de la Xunta de Galicia.

\subsection{Gestión de la interacción con el sector ganadero (Indicador cuantitativo y cualitativo)}

Cabe partir del hecho de que, mientras las medidas de prevención de daños tales como pastores eléctricos, cañones de propano, reserva de espacios naturales, el «rewilding», o la utilización de mastines para proteger el ganado, precisarían de una elevada responsabilidad y colaboración del sector (ganaderos y pastores); la compensación de daños constituye una aproximación reactiva que debería ser considerada como una solución de corto plazo al daño sufrido (Salvatori e Mertens, 2012) de la que se cuestiona su efectividad como estrategia (Boitani et al, 2010). iberica/

6 Una referencia a esta controversia puede seguirse en el enlace: https://loboiberico.com/el-lobo/el-lobo-en-la-peninsula- 
En este sentido, se observa en una parte de la literatura científica, una fuerte tendencia a entender que la prevención del daño (de los ataques al ganado), tiene una mayor probabilidad de constituirse en solución a largo plazo que las políticas de compensación de los ataques, e incluso que el pago de los daños debería estar siempre interrelacionado con la prevención, para ser esta fomentada eficientemente entre los ganaderos (Marucco e Boitani, 2012).

De manera que, en el plano internacional, en los últimos años ha habido una cierta refocalización de las estrategias, acabando por reorientarse el conflicto, desde las políticas de compensación como medida reactiva cortoplacista, a medidas de mayor calado y a largo plazo, como la promoción de buenas prácticas en el pastoreo o las medidas de protección del ganado, que en el caso de Galicia son además especialmente débiles $^{7}$. Concretamente, siguiendo a Wagner et al. (2012), los métodos de prevención más utilizados en la ganadería semiextensiva son los vallados y los perros de defensa del ganado -en España el mastín-. No obstante, el propio Wagner et al. (2012) confirma que no hay un único método de prevención que ofrezca un cien por ciento de efectividad, siendo los vallados eléctricos y los perros de guarda una excelente combinación para la prevención.

La gestión la interacción del lobo con el ser humano está, en el caso de estudio de Galicia, fuertemente marcada por el seguimiento de una política de compensación de los daños, por tanto una política «reactiva» frente a una política «consensual» (Tamayo, 1997; Varela, 2003).

Institucionalmente, el modelo gallego bebe de la línea marcada en el contexto europeo en los años 90, momento en que se publica por el Consejo de Europa un documento sobre la necesidad de proceder al pago de daños, pero combinado con importantes medidas preventivas. Este documento, publicado en 1990 por el Consejo de Europa y titulado: "Statut et conservation du loup (Canis lupus) dans les Etats membres du Conseil de l'Europe», firmado por Miguel Delibes; recoge y reproduce íntegramente en su Anexo 1 la Recomendación núm. 17 relativa la protección del lobo en Europa del Convenio de Berna. En esta recomendación se observa la insistencia por promover políticas de prevención de ataques:

«2. Promover, con el fin de evitar conflictos, el desarrollo de medidas tendientes a prevenir ataques al ganado por parte de los lobos, por ejemplo, alentando rebaños para encerrar el ganado por la noche, instalar cercas eléctricas o utilizar perros; fomentar la conservación y formación de las razas locales de perros pastores».

La propia administración de la Xunta de Galicia tiene en cuenta la existencia y necesidad de implementar medidas de prevención tales como: mastines, pastores eléctricos, curros y cercados (Xunta, 2015), pero la línea más poderosa de la acción pública autonómica ha sido sin embargo la de la compensación por daños al ganado. En este sentido, las compensaciones económicas a los ganaderos comenzaron en 2004, estando dirigidas a resarcir de las pérdidas económicas al sector ganadero y a que el peso de la conservación del lobo no perjudique a ningún sector social (Xunta de Galicia, 2015, p. 7).

Por su parte, los avisos por ataques del lobo también podrían estar reflejando ambos factores, la progresiva e intensiva humanización del territorio y las medidas de preservación de la especie. Estos dos factores llevan a un entorno necesariamente complejo de coexistencia de consolidadas poblaciones loberas con una cada vez mayor presencia humana.

Los propios datos del gobierno autonómico gallego reflejan este aumento de los incidentes:

7 En ese sentido, varias iniciativas focalizadas en la valoración de la efectividad y en la promoción de medidas preventivas de los ataques del lobo sobre el ganado si tienen abordado en los últimos años en el contexto de la UE. Así, al albur del programa LIFE Nature de la UE, una de las primeras iniciativas desenvolvidas en la procura de los objetivos anteriores fue la iniciativa LIFE Nature Project COEX LIFE04NAT/IT/000144 Improving coexistence of large carnivores and agriculture in Southern Europe. Dentro de este proyecto, de una duración de 4 años y desenvuelto en el período 2004-2008, las actividades realizadas fueron, entre otras, la estima de los daños causados por los grandes carnívoros y la selección de las explotaciones y el desenvolvimiento de métodos de prevención de daños, tales como cercados filos, vallados eléctricos, cabañas móviles para pastores o cierres móviles para corderos y perros de guardia y defensa de ganado. A mayores, en la línea de identificar y fomentar prácticas y métodos de pastoreo que favorecieran la reducción de la predación por lobo, en la UE también se dio impulso a proyectos que procurasen la mitigación de este conflicto en el suroeste de Europa. Un ejemplo fue el proyecto Exploring traditional husbandry methods to reduce Wolf predation on free-ranging cattle in Portugal and Spain- Support to the European Commission's policy on large carnivores under the Habitats Directive, como medida de apoyo a la política comunitaria de gestión de las poblaciones de grandes carnívoros, bajo la protección de la Directiva Hábitats. 
GAPP. Nueva Época - N. ${ }^{\circ}$ 27, noviembre 2021 - ISSN: 1989-8991 - DOI: https://doi.org/10.24965/gapp.i27.10875 - [Págs. 115-130]

Gestión del territorio y biodiversidad en la agenda 2030: Evaluación de la política pública de gestión del lobo en su interacción ...

Gráfica 2. Avisos de ataques de lobos a la ganadería

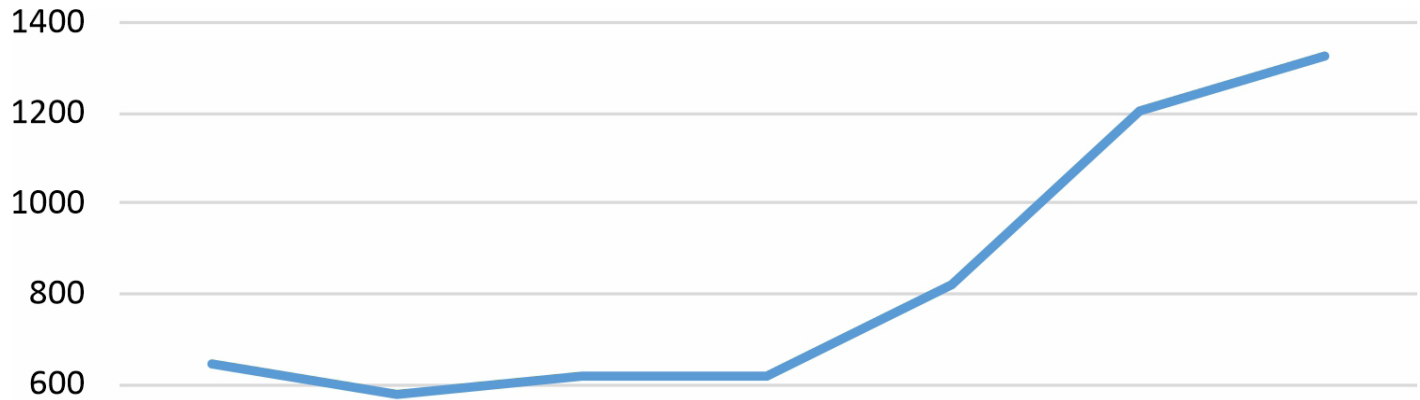

400

200

0

$\begin{array}{llllll}2012 & 2013 & 2014 & 2015 & 2016 & 2017\end{array}$

Fuente: Elaboración propia a partir de datos del Ministerio de Medio Ambiente y Consellería de Medio Ambiente, Territorio y Vivienda de la Xunta de Galicia.

La incidencia del lobo en Galicia, y los conflictos con el ser humano están en el caso gallego -y en gran parte de zonas de España- fuertemente amplificados de manera negativa por los medios de comunicación, unos medios que además son uno de los elementos más eficaces en las democracias pluralistas para ayudar a introducir problemas en la agenda institucional (Tamayo, 1997, p. 291), y que, en definitiva, marcan el ritmo (Brugué y Gomá, 2009, p. 269). En este sentido, la ganadería no extensiva de vacas, ovejas y, en menor medida de cabras es la más extendida en amplias zonas de Galicia. Los ataques de lobos a este tipo de explotación ganadera, que suele situarse en zonas próximas a núcleos de población, magnifican la problemática social del lobo. Según el Grupo de trabajo del Lobo (2005) integrado por expertos de las administraciones públicas y científicos, la amplificación y el sensacionalismo en los medios de comunicación y las precipitadas conclusiones alarmistas avivan e intensifican el conflicto y distorsionan el alcance del problema real de la depredación del ganado por los lobos $^{8}$.

\subsection{Indicadores de futuro (Indicador de ejemplificación)}

Los indicadores de futuro se emplean en el análisis de políticas públicas como indicadores de ejemplificación o mejora del conocimiento para futuros programas. En esta línea precisamente se proponen dichos indicadores como auténticas «prospecciones de futuro» al respecto.

Los agentes agresores del lobo como especie animal son múltiples, si bien en este trabajo, con la perspectiva amplia de contemplar el concepto «biodiversidad», se ha focalizado en la destrucción de hábitats naturales como factor preponderante.

No obstante, la falta de presas, la caza furtiva y la legal, los envenenamientos y los atropellos (hasta un $64 \%$ de sus muertes según el estudio autonómico sobre el que se basa el «Plan de Gestión del Lobo») son factores que también afectan a la política pública de gestión de la especie.

En este sentido de prospección de futuro o posibles tendencias, destaca claramente el debate en la dialéctica «Prevención de daños Vs Compensación por daños», siendo la apuesta por la política de compensación claramente vencedora y en línea de progresión, pues como se puede ver en la gráfica bajo estas líneas cada vez es mayor el presupuesto dedicado a la compensación por daños en el ganado aumentándose un $30 \%$ en determinados ayuntamientos especialmente afectados según la última orden (Xunta, 2020).

8 Noticia de la presencia de los lobos en la playa en el periódico "La Voz de Galicia 11-06-20". En el periódico "La Opinión de A Coruña 17-5-19" en el subtítulo de la noticia: Los avisos por ataques de lobos alcanzan la cifra más elevada de esta década llegan a calificar los ataques como «asaltos»: «... Los ganaderos denuncian 1.328 asaltos en Galicia». 
Gráfica 3. Evolución del pResupuesto de ayudas para la pREVEnción de daños del lobo en GaLicia

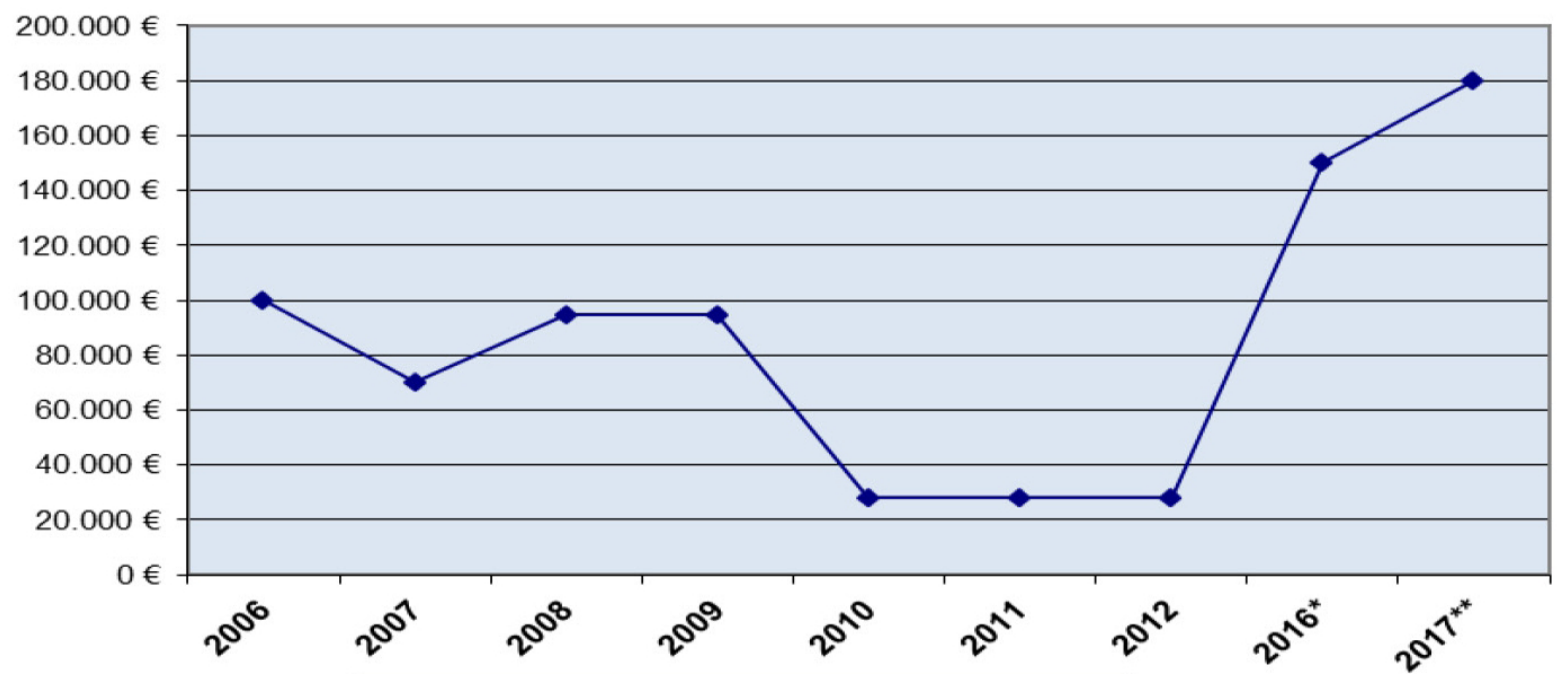

Fuente: Elaboración propia a partir de datos de la Xunta de Galicia.

Resulta llamativa la escasa utilización en Galicia de medidas de prevención de ataques del lobo al ganado observada en las 88 explotaciones visitadas en el estudio de la Xunta de Galicia (2015) para la valoración de la eficacia de distintos métodos de prevención. El análisis de los datos recogidos en las visitas a explotaciones ganaderas refleja que en el $63,6 \%$ de las explotaciones el tipo de cierre no ofrece protección al ganado; un $72,7 \%$ no tiene perros de guarda y, en el $46,6 \%$ de las explotaciones las reses pasan siempre la noche fuera.

IMAGEN 2. ReLACión ENTRE LOS CONCEPTOS DE RELEVANCIA, EFICACIA Y EFICIENCIA

RELACIÓN ENTRE RELEVANCIA, EFICACIA Y EFICIENCIA

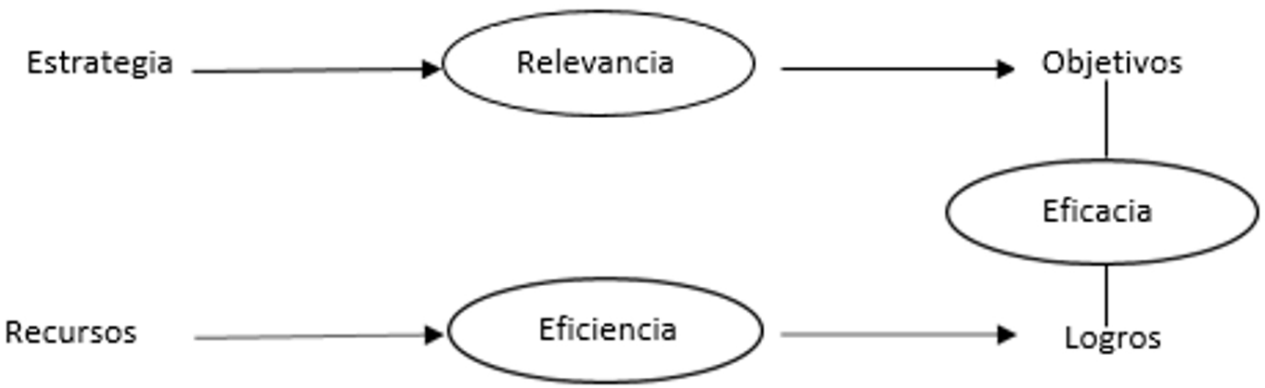

Fuente: Fenstein (2007).

Atendiendo al esquema de evaluación de políticas públicas de Feinstein (2007), se consiguen objetivos, pero viciados por una falta de relevancia o calidad y veracidad del diagnóstico (Eusko Jaurlaritza-Gobierno Vasco, 2012) de las medidas seguidas, ofreciendo una falsa apariencia de éxito. Esto es la estrategia de protección deja de lado una pieza fundamental como la protección del territorio natural (urbanización salvaje, exceso de infraestructuras, destrucción del medio para proyectos económicos, deportivos o de ocio, etc.).

Por lo tanto, se puede señalar que se cumplen los objetivos previstos en la política pública a seguir, si bien esta debería ser rediseñada pues se muestra poco relevante a la hora de conseguir los impactos finales de preservación sostenida de la especie. Se cumple una cierta contradicción entre los criterios de evaluación 
GAPP. Nueva Época - N. ${ }^{0}$ 27, noviembre 2021 - ISSN: 1989-8991 - DOI: https://doi.org/10.24965/gapp.i27.10875 - [Págs. 115-130]

Gestión del territorio y biodiversidad en la agenda 2030: Evaluación de la política pública de gestión del lobo en su interacción ...

Oscar Briones Gamarra

de resultado y los criterios de evaluación de impacto (con resultados más negativos), pasando la gestión del territorio a vislumbrarse como factor más importante finalmente que las políticas de prevención y preservación desarrolladas hasta la fecha, que no obstante demuestran su eficacia en evitar la extinción total de la especie.

\section{CONCLUSIONES}

En primer lugar, de la revisión de la política pública analizada, se concluye claramente que esta se orienta a causas contextuales de y resolución a corto-medio plazo, abriéndose paso claramente la depredación y urbanización del territorio como causa de fondo principal en el problema que se intenta resolver.

Entre las conclusiones, de forma concreta, se pueden observar:

1. Esta funcionado la política pública de gestión, pero entendida como contención en la preservación y para minorar el cariz en su definición de "problema económico». Así mismo, se implementa esta estrategia como parte de la competencia política gubernamental, demostrando que el partido en el gobierno también puede ocupar espacios conservacionistas (además todos los gobiernos autonómicos tienen planes similares).

2. Parece imprescindible ahondar en la explotación del turismo natural con el foco en el lobo como elemento indicativo de la buena calidad y «rica» biodiversidad de una zona natural (Xunta, 2020), como máxima expresión de una preservación en profundidad.

3. En línea con la ponderación de los factores contextuales propuesta por Fenstein (2007), ha de profundizarse en las labores de sensibilización ambiental ya que se aprecia un desequilibrio entre los distintos actores, pesando más aquellos que realizan una definición del lobo como problema para el ser humano. De hecho el propio acto de realizar una evaluación es también una forma de dejar claro que se pueden hacer mejoras (Eusko Jaurlaritza-Gobierno Vasco, 2012) y, como mínimo, generar debate (Dahler-Larsen, 2007, pp. 98-99).

4. Debe insistirse en la idea de la «sostenibilidad de la eficacia», pues si continúa el deterioro y la devastación de espacios naturales para su humanización, difícilmente se podrán obtener resultados de impacto. En este sentido, los logros del programa de gestión del lobo no parece que se puedan mantener si se finaliza la intervención pública.

5. La evaluación de políticas públicas se diferencia de la labor de auditoría en que también se tienen en cuenta los objetivos establecidos. Se valora la adecuación entre objetivos y el impacto final buscado, de hecho, fijar criterios para evaluar es una forma de ...definir marcos interpretativos y las visiones del mundo (Dahler-Larsen, 2007, p. 99). Cabe recordar aquí el hecho de que frecuentemente los objetivos no se definen de manera inequívoca sino de forma confusa y general; y en ocasiones, como en este caso, aun cumpliéndose en buena medida los objetivos, estos se han mostrado poco ambiciosos y de escaso calado frente a los verdaderos problemas de fondo, entre los que figuran de forma destacada el consumo insostenible de recursos y la degradación ecológica del propio territorio.

\section{REFERENCIAS BIBLIOGRÁFICAS}

Abercrombie, N., Hill, S., y Turner, S. B (1984). The Penguin Dictionary of Sociology. Penguin Books.

Aguilar, L. F. (2008). Marco para a análise das políticas públicas. Administración \& Cidadanía, 3(2), 9-28. https:/legap. xunta.gal/revistas/AC/article/view/4243

Ballart, X. (1993). Evaluación de políticas (Marco conceptual y organización institucional). Revista de Estudios Políticos, 80, 199-224. http://www.cepc.gob.es/publicaciones/revistas/revistaselectronicas?IDR=3\&IDN=237\&IDA=16806

Bardach, E. (2001). Los ocho pasos para el análisis de políticas públicas. Un manual para la práctica (ed. original de 1996). CIDE.

Boitani, L.; Ciucci, P. y Raganella-Pelliccioni, E. (2010). Ex-post compensation payments for wolf predation on livestock in Italy: a tool for conservation? Wildlife Research, 37(8), 722-730. https://doi.org/10.1071/WR10029

Boix, C. (1991). Promesas y límites del policy analysis en Estados Unidos. Documentación Administrativa, 224-225, 167-194.

Brugué, Q. y Gomá, R. (2009). Nuevas formas de gobernar: límites y oportunidades. En S. Fleury, J. Subirats e I. Blanco (eds.), Respuestas locales a inseguridades globales Innovación y cambios en Brasil y España (pp. 265284). Fundación CIDOB.

Centro de Investigaciones Sociológicas - CIS (13 de mayo de 2010). Medio ambiente (II). International social survey programme (Estudio núm. 2.837). http://www.cis.es/cis/opencm/ES/1_encuestas/estudios/ver.jsp?\&estudio=11404 
GAPP. Nueva Época - N. ${ }^{0}$ 27, noviembre 2021 - ISSN: 1989-8991 - DOI: https://doi.org/10.24965/gapp.i27.10875 - [Págs. 115-130] Gestión del territorio y biodiversidad en la agenda 2030: Evaluación de la política pública de gestión del lobo en su interacción ...

Oscar Briones Gamarra

Convention on Biological Diversity - CBD (1992). Convenio sobre diversidad biológica. https://www.cbd.int/convention/ Dahler-Larsen, P. (2007). ¿Debemos evaluarlo todo? O de la estimación de la evaluabilidad a la cultura de la evaluación. ICE, Revista de Economía, 836, 93-106 (ejemplar dedicado a Evaluación de Políticas Públicas). http:// www.revistasice.com/index.php/ICE/article/view/1052

Della Porta, D. y Keating, M. (2013). Enfoques y metodologías de las ciencias sociales. Una perspectiva pluralista. Akal.

Dunn, W. N. (1994). Public Policy Análysis. An introduction. Prencite Hall.

Eusko Jaurlaritza-Gobierno Vasco (2012). Guía de Evaluación de Políticas Públicas del Gobierno Vasco. https://www. euskadi.eus/contenidos/informacion/evaluacion_coordinacion/es_def/adjuntos/guia_evaluacion_gv_pip.pdf

Flyvbjerg, B. (2004). Cinco malentendidos acerca dē la investigación mediante los estúdio de caso. Revista Española de Investigaciones Sociológicas, 106, 33-62. http://www.reis.cis.es/REIS/jsp/REIS.jsp?opcion=articulo\&ktitulo=19 16\&autor=BENT+FLYVBJERG

Feinstein, O. (2007). Evaluación pragmática de políticas públicas. ICE, Revista de Economía, 836, 19-32 (ejemplar dedicado a: Evaluación de políticas públicas). http://www.revistasice.com/index.php/lCE/article/view/1047

Fernández, A. (2005). Políticas Públicas. En M. Caminal Badía y X. Torrens (eds.), Manual de Ciencia Política. Tecnos.

Galetti, M. y Dirzo, R. (2013). Ecological and evolutionary consequences of living in a defaunated world. Biological Conservation, 163, 1-6. https://doi.org/10.1016/j.biocon.2013.04.020

Grupo de Trabajo del Lobo (2005). Estrategia para la Conservación y la Gestión del Lobo (canis lupus) en España. Ministerio de Medio Ambiente (Comisión Nacional de Protección de la Naturaleza). https://www.miteco.gob.es/es/ biodiversidad/publicaciones/pbl-fauna-flora-estrategias-lobo.aspx

Lindblom, Ch. (1959). The science of «muddling through». Public Administration Review, 19(2), 79-88. https://doi. org/10.2307/973677

Lindblom, Ch. (1991). El proceso de elaboración de políticas públicas. INAP.

Lowi, T. (1964). American Business, Public Policy, Case Studies and Political Theory. World Politics, 16(4), 677-715. https://doi.org/10.2307/2009452

Ministerio de Agricultura, Alimentación y Medio Ambiente (MAGRAMA) (2016). Censo 2012-2014 de lobo ibérico (Canis lupus, Linnaeus, 1758) en España. https://www.miteco.gob.es/es/biodiversidad/temas/inventarios-nacionales/ inventario-especies-terrestres/ieet_mamiferos_censo_lobo.aspx

March, J. G. y Olsen, J. P. (1972). A garbage can model of organizational choice. Administrative Science Quarterly, 17(1), 1-25. https://doi.org/10.2307/2392088

Marucco, F. y Boitani, L. (2012). Wolf population monitoring and livestock depredation preventive measures in Europe. Hystrix, the Italian Journal of Mammalogy, 23(1), 1-4. https://doi.org/10.4404/hystrix-23.1-6364

Meny, Y. y Thoenig, J.-C. (1992). Las políticas públicas. Ariel.

OCDE (2013). Glosario de los principales términos sobre evaluación y gestión basada en resultados. https://www.oecd. org/dac/evaluation/2754804.pdf

Orden del 7-2-2020 por la que se establecen las bases reguladoras de las ayudas para paliar los daños producidos por el lobo Xunta de Galicia (2020). DOG núm. 26. https://www.xunta.gal/dog/Publicados/2020/20200207/ AnuncioG0532-201219-0004 es.html

Pressman, J. L. y Wildavsky, A. (1984). Implementation (3. ${ }^{a}$ ed., original 1973). University of California Press, Ltd.

Rojo, A. y Varela, E. (2013). La buena gobernanza del Estado Autonómico: un largo camino por recorrer. En I. Crespo Martínez y P. Oñate Rubalcaba (dirs.), Política y Gobierno en el Estado Autonómico (pp. 337-373). INAP/Tirant lo Blanch.

Rossi, H. y Freeman, H. E. (1985). Evaluation: A Systematic Approach. SAGE.

Salvatori, V. y Mertens, A. D. (2012). Damage prevention methods in Europe: experiences from LIFE nature projects. Hystrix, 23(1), 73-79. https://doi.org/10.4404/hystrix-23.1-4548

Subirats, J. (2001). El análisis de las políticas públicas. Gaceta sanitaria, 15(3), 259-264. https://doi.org/10.1016/ S0213-9111(01)71557-9

Subirats, J., Knoepfel, P., Larrue, C. y Varone, F. (2008). Análisis y Gestión de políticas públicas. Ariel.

Tamayo Sáez, M. (1997). El análisis de las políticas públicas. En R. Bañón y E. Carrillo (comps.), La nueva Administración Pública (pp. 281-312). Alianza editorial.

Varela Álvarez, E. J. (2003). Las Administraciones Públicas Contemporáneas en España: Una visión multidisciplinar desde el estado de las autonomías. Tórculo edicións.

Wagner, C., Holzapfel, M., Kluth, G., Reinhardt, I. y Ansorge, H. (2012). Wolf(Canis lupus) feeding habits during the first eight years of its occurrence in Germany, Mammalian Biology, 77(3), 196-203. https://doi.org/10.1016/j. mambio.2011.12.004.

Weber, M. (1972). Ensayos de Sociología contemporánea. Ediciones Martinez Roca.

Xunta de Galicia (2015). Informe de valoración da eficacia de distintos métodos de prevención de danos do lobo. (Revisado el 5 de mayo de 2020). https://cmatv.xunta.gal/c/document_library/get_file?folderld=444684\&name=D LFE-45218.pdf

Xunta de Galicia (2017). Resumen del censo del lobo ibérico en Galicia implementado entre los años 2013-2015. (Revisado el 1 de mayo de 2020). https://cmatv.xunta.gal/c/document_library/get_file?folderld=157898\&name=D LFE-35496.pdf 